\title{
Design and simulation analysis of cowpea dehulling Machine
}

\author{
Batet Samuel and Okuma Silas Oseme * \\ Department of Mechanical Engineering Nigeria Maritime University, Okerenkoko, Delta State, Nigeria.
}

Global Journal of Engineering and Technology Advances, 2021, 07(02), 050-066

Publication history: Received on 07 April 2021; revised on 10 May 2021; accepted on 13 May 2021

Article DOI: https://doi.org/10.30574/gjeta.2021.7.2.0069

\begin{abstract}
The dehulling of cowpea seeds will have a great influence in increasing the overall production, consumption, processing into more dietary, hygienic products and the advancement of cowpea processing industry. The technology of cowpea processing industry is still at its lowest ebb. Therefore, designing a machine to dehull cowpea beans would be of greater benefit to the common man protein intake and the afore-mentioned development of the cowpea industry.

The machine is designed to be mechanically operated by an electric motor as the prime mover with dehulling capacity of $6.67 \times 10^{-4} \mathrm{~m}^{3} / \mathrm{s}$ or $37.2 \mathrm{~kg} / \mathrm{min}$. The beans will be fed by rotating force received from the feed wheel in the hopper into the plate's gap interface that will be pre-set that the total volume of feeder is approximately the volume of the space between plate surfaces. The rotating action of moving against stationary plate effect the rasping of soaked cowpea off their cotyledons.
\end{abstract}

The design consideration applied appropriate technology, ease of dehulling soaked cowpea and the attrition action of plate surfaces and readily available engineering materials with possible equipment in the country.

The dehulled efficiency was $79 \%$ at $81.25 \%$ machine efficiency shown from the simulation analysis, this greatly show a high level improvement when compared with other related designs.

Keywords: Cowpea; Dehulling; Husk; Crushing; Soaked; Simulation

\section{Introduction}

Cowpea (Vigna unguiculata) is one of the common food source in rural and urban homes in Nigeria, as it is cheap and it has significant constituent of protein, minerals and vitamins[1].This crop is mainly cultivated in west and Central Africa with an annual production of 3 millions tons[2].In Nigeria, cowpea are eaten in various forms; as porridge along with fried or boiled yam or plantain, Dehulled cowpea is necessary in the preparation of some Africa food process (fried beans,akara, boiled moi moi).In spite of the widespread use of this staple food among Nigerians[3],dehulling of cowpea has been identified as the major problem culminating against the utilization and processing of cowpea into a more versatile food product that eliminates flatulence and repulsive odour effects. The existing method such as the traditional method of soaking in water and hand rasping to remove the seed coats is time consuming, tedious and discourages large scale processing even though it gives better efficiency. Also, the machine method employing either the wet or dry milling, peeling or polishing machines has a lot of setbacks in terms of tedious labour during pre- treatment, time wastage, complexity of machines, cost of operation and acquisition and their inefficiency. The developments of agriculture in developing countries of the world depend on the part played by modern agricultural machinery and equipment. Many local cowpea dehulling machine have been developed but reliable information and performance data on them are limited.

${ }^{*}$ Corresponding author: Okuma Silas Oseme

Department of Mechanical Engineering Nigeria Maritime University, Okerenkoko, Delta State, Nigeria. 
There is need therefore to design, fabricate and evaluate the performance of a local cowpea dehuller that provide lower cost and yet achieving good quality products[4]. In the case of burred plates grinding machine, the dry seeds are poured into the hopper of the machine with the plate surface fairly adjusted to crack the seeds [5], thereafter pour water to float the husks. It is still less efficient as rice polisher. The application of these existing machines still makes cowpea dehulling inefficient and an uphill task in terms of labour, time consumption, product result, cost of machines and operation [6].

The objectives of this study is to explores the needs arising in applying appropriate technology in designing a simple cowpea dehulling machine which are:

- $\quad$ Cost effective, qualitative, easily affordable

- Will aid higher production capacity and reduce time wastage to manual effort.

- Can be used in urban and rural areas with important contribution to the development of small-scale agricultural food processing industry

\section{Methodology}

\subsection{Machine Description}

The cowpea dehulling machine simply will consist of various components that are designed to perform specific tasks. This includes two circular surface plates, one attached to a rotating shaft supported by two roller bearings and the other to a spring-loaded adjustable screw stationary shaft. The Material on plate surfaces will be made up of Butyl rubber, and the entire assembly is to be enclosed in a cylindrical casing mounted on a rigid frame that also accommodate the prime mover (electric motor).The power from the electric motor is transmitted to the rotating shaft of the dehulling machine by means of V-belt and pulleys. The cowpea would be poured through vertically mounted hopper on top of the casing which is fed at an angle through off centered hole on the adjustable stationary (non-rotating) plate. To satisfy efficient feeding of cowpea to the action zone, an automatic feeding device (feed wheel would be incorporated in the hopper in order to compensate for negligible gravitational effect and supplied constant feed rate. Basically, the seeds are fed by rotating force received from feed wheel in the hopper into the plate's gap interface that is pre-set to accommodate average size of cowpeas across width. Then the rotating action of moving plate with the stationary plate effect the rasping of coats of soaked cowpea off their cotyledons before they finally dropped with aid of centrifugal force or reduction in sizes into the delivery end.

\subsection{Research Methodology}

The lean availability of data from existing literatures necessitated the carrying out of series of experiments in order to obtain data for the mathematical basis of the design. Cowpea samples used was purchased from Yelwa Tudu market, Bauchi State as dry seeds with about 15\% moisture content. First Point considered was the determination sizes of cowpea; this was done by random sampling measurements, both for dry and soaked seeds. Ten samples were measured, each across the length and width using venier caliper. Then a mass of 100 grams dry seeds was weighed in the laboratory and the volume noted, it was soaked in excess tap water for 30minutes with observation within 10 minutes interval, after which water was drained off and the weight and volume of wet seeds noted.

The force suitable to rasp the soaked beans was experimentally determined by application of weights and sliding plates mechanism with rubber sheets bonded to their surface as shown in fig 1.

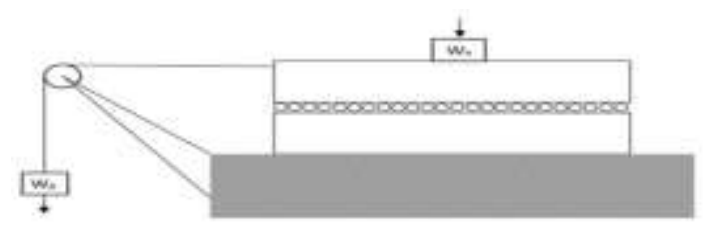

Figure 1: Sliding Plate Mechanism 
The maximum crushing force under static and dynamic load was also determined. In order to ascertain or compare the value of coefficient of friction of soaked cowpea with butyl rubber and that obtained from sliding plates mechanism, a calibrated incline plane was used as illustrated in fig:2.

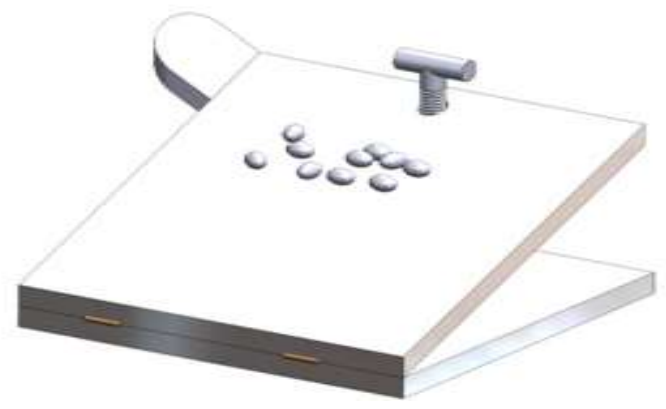

Figure 2: Incline plane

\section{Results and discussion}

\subsection{Data Evaluation}

3.1.1. Determination of cowpea size using a venier caliper

Table 1. Sizes of dry and soaked cowpea seed

\begin{tabular}{|r|r|l|r|}
\hline \multicolumn{1}{|l|l|l|}{ ACROSS } & \multicolumn{1}{l|}{ ACROSS } & \multicolumn{1}{l|}{ ACROSS } \\
\hline LENGTH(mm) & WIDTH(mm) & LENGTH(mm) & WIDTH(mm) \\
\hline 10 & 7 & 10 & 7 \\
\hline 8.4 & 7 & 11.5 & 7 \\
\hline 11 & 5.5 & 10 & 6.5 \\
\hline 7 & 3.5 & 11.4 & 7 \\
\hline 6.4 & 4.5 & 9 & 5 \\
\hline 8.4 & 6.5 & 9 & 5.3 \\
\hline 10 & 4.5 & 11 & 6.3 \\
\hline 6 & 4 & 10 & 7 \\
\hline 9 & 5 & 10 & 6 \\
\hline 9.5 & 5 & 11 & 7.5 \\
\hline & & & \\
\hline
\end{tabular}

\subsubsection{Weight of dry cowpea $=100 \mathrm{~g}$}

Volume of dry cowpea $=143 \mathrm{~cm}^{3}$

The dry cowpea bulk density= mass of seeds volume of seeds

Volume of seeds

$=100 / 143$

$=0.699 \mathrm{~g} / \mathrm{cm}^{3}=699 \mathrm{~kg} / \mathrm{m}^{3}$

3.1.3. Weight of soaked $100 \mathrm{~g}$ cowpea $=175 \mathrm{~g}$

Volume of soaked cowpea $=260 \mathrm{~cm}^{3}$

The bulk density of soaked cowpea $=\frac{\text { Mass }}{\text { Volume }}=\frac{175 \mathrm{~g}}{260 \mathrm{~cm}^{3}}=0.673 \mathrm{~g} / \mathrm{cm}^{3}=673 \mathrm{~kg} / \mathrm{m}^{3}$ 


\subsubsection{Force sufficient to dehusk soaked cowpea (82 seeds per experiment)}

Taking the weight of sliding plate into consideration (determined tobe $1.75 \mathrm{~N}$ ), the optimal result was obtained from average of the reading as

$$
W_{A}=\frac{12.0+12.5+13.0}{3}=12.5 \mathrm{~N}
$$

With corresponding load $W_{B}$ taking weight of hanger as $0.25 \mathrm{~N}$, optimal result from average readings gotten was

$$
W_{B}=\frac{5.25+6.00+6.50}{3}=5.92 N
$$

3.1.5. The force tends to crush soaked cowpea is when it exceeds $15.8 \mathrm{~N}$ under dynamic load (plate sliding), but about 50N under static load.

\subsubsection{Size of sliding plate}

$\begin{array}{ll}\text { Length } & =0.12 \mathrm{~m}, \text { width }=0.06 \mathrm{~m} \\ \text { Area } & =\text { Length } \mathrm{x} \text { width }=0.12 \times 0.06=0.0072 \mathrm{~m}^{3}\end{array}$

3.1.7. Determination of coefficient of friction from sliding plate mechanism

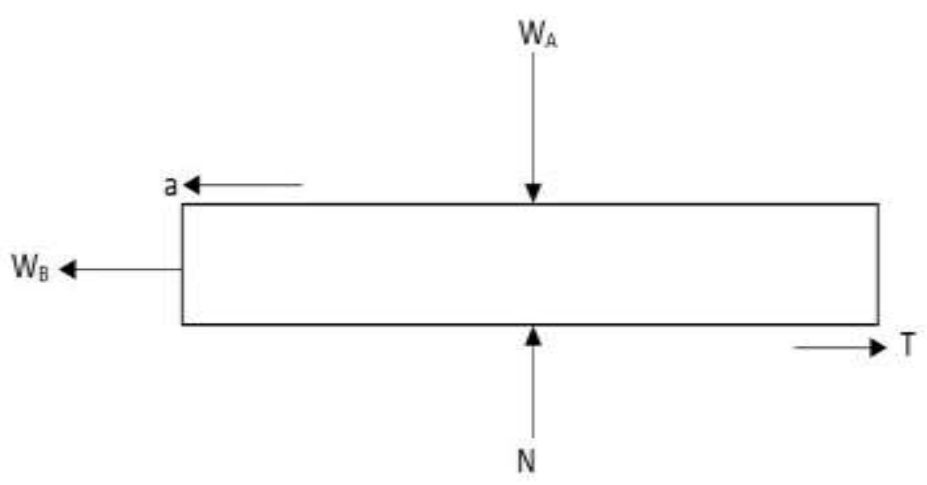

From Newton's third law of motion,

$$
\begin{aligned}
& W_{B}=\mathrm{T} \\
& W_{A}=\mathrm{N}
\end{aligned}
$$

But $\mathrm{T}=\mathrm{fN}$

Where

$$
\begin{array}{lll}
\mathrm{F} & = & \text { coefficient of friction } \\
\mathrm{N} & = & \text { Normal Reaction }
\end{array}
$$

$$
F=\frac{T}{N}=\frac{5.92}{12.5}=0.4733=0.5
$$

Comparing with that obtained between cowpea with rubber surfaces

(Taking average readings for computation when using incline plane).

Table 2: Rolling angle of dry and socked seeds 


\begin{tabular}{|l|l|l|l|}
\hline Reading & 1st & 2nd & 3rd \\
\hline Dry cowpea & 18 & 19 & 23 \\
\hline Soaked cowpea & 28.5 & 27 & 27.2 \\
\hline
\end{tabular}

Coefficient of friction when dry

$$
f_{d r y}=\tan \left(\frac{18^{0}+19^{0}+23^{0}}{3}\right)=\tan 20^{0}=0.36
$$

Coefficient of friction when soaked

$$
f_{\text {wet }}=\tan \left(\frac{28.3^{0}+27^{0}+27.2^{0}}{3}\right)=\tan 27.5^{0}=0.52
$$

This shows proximity in value to that obtained from sliding plate mechanism.

The calculation from data shows a reduction in bulk density of soaked cowpea due to higher rate of increase in volume than in weight due to water absorbed. Experimental observation portrayed that $15.8 \mathrm{~N}$ force tends to crush the soaked cowpea instead of smooth Dehulling under dynamic loading on the other, the static loading effect would show no effect of breaking or crushing the soaked cowpea except under impact. Thus more than $50 \mathrm{~N}$ forces were required to crush seeds statically when applied on single seed.

Random sampling measurement of cowpea sizes illustrates a varying size of 6-11 mm across length, 3-7 mm across width for dry seeds, while approximately $9-11 \mathrm{~mm}$ across length and 5-7 mm across width for soaked seeds. In comparison with that obtained from literature (3-7 mm across width and $9-12 \mathrm{~mm}$ across length for soaked beans)[7]. Also the coefficient of friction was seen to be higher for soaked cowpea than dry because the husk tends to stick to the rubber surface due to the seed being laden hence required higher angle of inclination.

\subsection{The Mathematical Basis for the Design}

Engineering design is a mathematical model which shows exactly the behaviour of the engineering system in form of equations that correlates different parameters to each other in a system. Thus, design is the concept of impression to bring into being a system, determining the elements and their pertaining parameters, shape, choice of materials and condition of operation [8].

It embraces also cost analysis and manufacturing method for construction and fabrication of the system

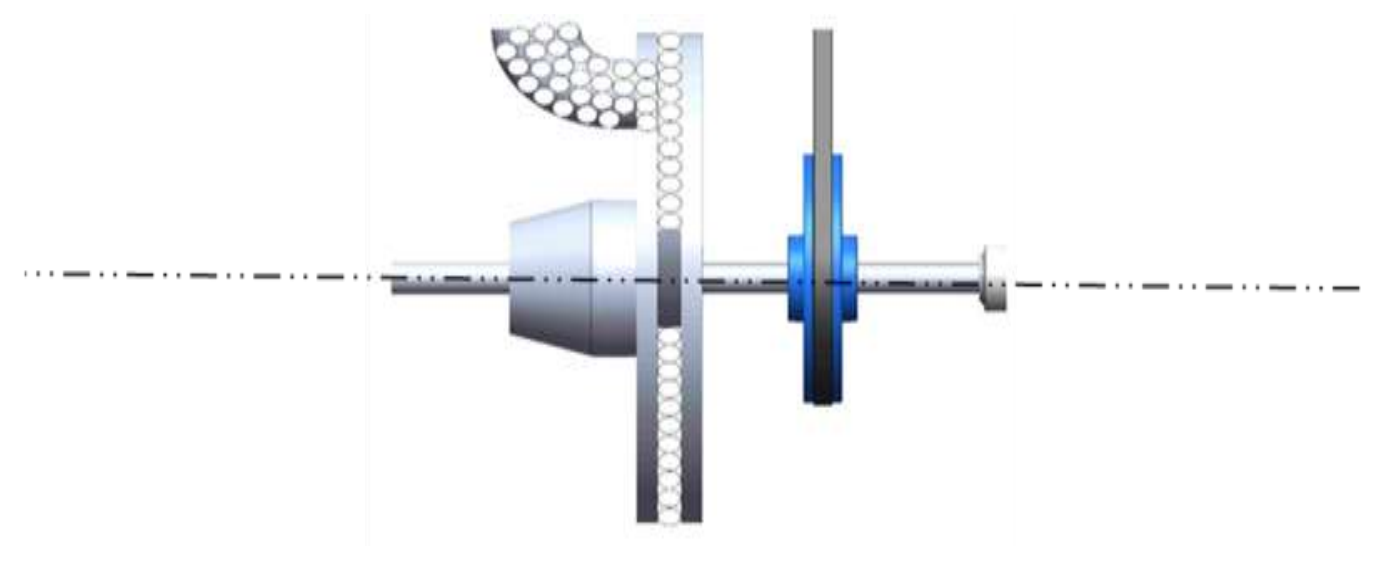

Figure 3:Dehulling condition between plates

The mathematical basis here is stimulated from what occurred in the sliding plates experiment as follows. 
3.2.1. The area of rectangular sliding plate.

$$
A_{p}=0.0072 m^{2}
$$

3.2.2. Taking the average size of soaked cowpea as $6.41 \mathrm{~mm}$ across width and $10.37 \mathrm{~mm}$ across length, the area of cowpea $A_{b}$ was determined as

$$
A_{h}=66.5 \mathrm{~mm}^{2}
$$

3.2.3. In order to determine certain data, approximate number of soaked cowpeas were placed on a $20^{\circ}$ sector of a circular plate surface, to determine the area occupied and unoccupied graphically.

Area of sector

$$
=\quad \frac{\theta}{360} \pi\left(r_{2}{ }^{2}-r_{1}{ }^{2}\right)
$$

Where $_{2}=$ outside radius of plate

$r_{1}=\quad$ inside radius of plate

Area of sector $=\frac{20}{360} \pi\left(0.15^{2}-0.03^{2}\right)$

$$
=\quad 3.77 \times 10^{-3} \mathrm{~m}^{2}
$$

From observation 48 cowpea seeds occupied the sector surface using graph sheet with small space $2 \mathrm{~mm} \times 2 \mathrm{~mm}$.

Area occupied is expressed as number of squares $\mathrm{x}$ area of one square.

$727 \times 4 \mathrm{~mm}^{2}=2.91 \times 10^{-4} \mathrm{~m}^{2}$

Area of space that remained between beans due to their irregular shapes was

$210 \times 4 m^{2}=8.4 \times 10^{-4} m^{2}$

Showing error of $0.00002 m^{2}$

The ratio of area covered by cowpea to area of sector $\mathrm{K}_{\mathrm{b}}$

$K_{b}=\frac{2.91 \times 10^{-3}}{3.77 \times 10^{-3}}=0.77$

The ratio of area of space to area of sector Ks

$K_{S}=\frac{8.4 \times 10^{-4}}{3.77 \times 10^{-3}} \quad=\quad 0.22$

3.2.4. To calculate the area of the circular plate, it is assumed that certain ratio of working areaK $K_{p}$ is used when working i.e. the seed as are not expected to get through $360^{\circ}$ before being dehull and sent out for delivering. The value of $K_{p}$, is taken as 0.88 ,Spot, (1988). It is assumed that cowpea will dehull within $315^{0}$ movement through plate surface

Area of plate (circular) $=\pi\left(r_{2}{ }^{2}-r_{1}{ }^{2}\right) K_{p}$

Where $r_{2} \quad=\quad 0.15 \mathrm{~m}$ and $r_{1} \quad=\quad 0.03 \mathrm{~m}$

$A_{p(\text { Circular })}=\pi\left(0.15^{2}-0.03^{2}\right) 0.88$

$=\quad 5.97 \times 10^{-2} \mathrm{~m}^{2}$

It is also assumed that the distributions of cowpea on sliding plate on machine are equal, so number of seed on circular plate will be;

No. of seeds on sliding plate - area of sliding plate 
No. of seeds on circular plate - area of circular plate

i.e.

$82-7200 \mathrm{~mm}^{2}$

$N_{b}-59700 \mathrm{~mm}^{2}$

Therefore,

$N_{b}=\frac{59700 \times 82}{7200}=680$

The permissible force on sliding plate that dehulled cowpea efficiently was $12.50 \mathrm{~N}$

Therefore, the permissible force $F_{p}$ on circular plates in machine will be:

Permissible force on sliding plates - No. of seeds on sliding plates

Permissible force on circular plate - No. of seeds on circular plate

1. e.

12.50

$F_{p}$ $-680$

Therefore,

$F_{p} \quad=\quad \frac{1250 \times 680}{82}=\quad 103.7 \mathrm{~N}$

Then, the permissible pressure $P_{p}$ developed is obtained from the expression,

$F_{p} \quad=\quad P_{p} \times \mathrm{JI}\left(r_{2}^{2}-r_{1}^{2}\right) K_{p}$

$$
P_{p} \quad=\quad \frac{F_{p}}{\pi\left(r_{2}^{2}-r_{1}^{2}\right) K_{p}}
$$

i.e. $\quad \frac{\text { permissible force on circular plate }}{\text { area of circular plate }}$

$=\quad \frac{103.7}{5.97 \times 10^{-2}}$

$=1736 \mathrm{~N} / \mathrm{m}^{2}$

Or

permissible force on sliding plate area of sliding plate

$$
\begin{gathered}
=\quad \frac{12.5}{0.0072} \\
=\quad 1736 \mathrm{~N} / \mathrm{m}^{2}
\end{gathered}
$$

Hence, Torque ' $\mathrm{T}$ ' to drive the plate is given as

$$
\mathrm{T}=\frac{2}{3} P_{p} \pi f\left(r_{2}{ }^{2}-r_{1}{ }^{2}\right) K_{p}
$$


Where

$f \quad=\quad$ coefficient of friction of soaked cowpea obtained as 0.5 .

$\mathrm{T}=\frac{2}{3} x 1736 x \pi x 0.5\left(0.15^{2}-0.03^{2}\right) 0.88$

$=\quad 5.36 \mathrm{Nm}$

3.2.5. The volume between the circular surface $V_{s}$ is given as

$V_{s}=\pi\left(r_{2}{ }^{2}-r_{1}{ }^{2}\right) K_{p} \mathrm{~L}$

$=\quad \mathrm{L} x$ area of circular plate

Where,

$\mathrm{L} \quad=\quad$ average size across width of cowpea taken as $0.006 \mathrm{~m}$

$\mathrm{V}=\pi\left(0.15^{2}-0.03^{2}\right) 0.88 \times 0.006$

$=\quad 3.58 \times 10^{-4} \mathrm{~m}^{3}$

3.2.6. The area of each section of feed wheel is determined using graphical method (graph of $2 \mathrm{~mm} \times 2 \mathrm{~mm}$ space)

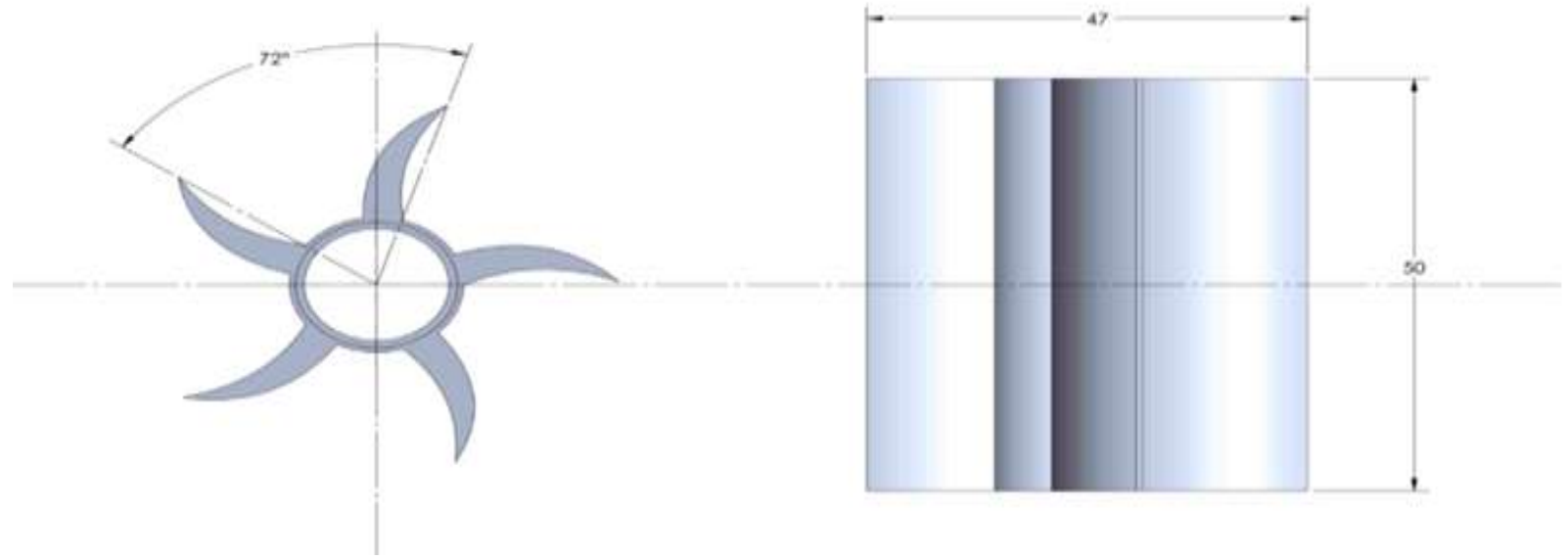

Figure 4 schematic view of feed wheel

The wheel has 5 sections with length $47 \mathrm{~mm}$ and diameter $50 \mathrm{~mm}$

Table 3: Area of section of feed wheel

\begin{tabular}{|l|l|}
\hline Section A & Section B \\
\hline $1542 \mathrm{~mm}$ & $1528 \mathrm{~mm}$ \\
\hline
\end{tabular}

Taking average value to reduce percentage error, we have

$1524+1528 / 2=1526 \mathrm{~mm}^{2}$

Total volume of feeder $V_{f}=\quad\left(1.53 \times 10^{-3} \times 0.047\right) 5$

$$
=3.60 \times 10^{-4} \mathrm{~m}^{3}
$$


The value is approximately the volume of the space between plate surfaces to accommodate cowpea;

Therefore, each feeder section will contain:

$$
\left.\begin{array}{c}
{\left[\frac{\text { total volume of feeder }}{\text { volume between the circular plate }} \times\right. \text { No of seeds on circular plane }} \\
\text { No. of section of whee }
\end{array}\right]
$$

\subsubsection{The maximum power required is given as}

Power $\mathrm{P}=T_{\omega}$

Where

$\omega=$ = angular velocity of plate

$\mathrm{T}=$ torque $=5.36 \mathrm{Nm}$

Recalling that

$\omega \quad=\quad \frac{V}{t}$

Where

$\mathrm{V}=\quad$ linear velocity of plate

$\mathrm{R}=\quad$ peripheral radius of plate.

Since maximum speed of rotation will be at the periphery

Hence,

$\mathrm{r}=0, \mathrm{v}=0$,

Therefore

$\mathrm{y}=\mathrm{X} \omega$

Where

$\mathrm{y}=$ linear velocity

In order to find the linear velocity ' $\mathrm{V}$ ' forces that acts on the sliding

plate are analyzed, thus from figure 4

$W_{b} \quad=\quad \mathrm{P}=\quad$ applied drawing force

$=\quad 5.92 \mathrm{~N}$

$\mathrm{N}=$ force opposing $\mathrm{P}$ which must be $\leq$ Pfor the plate to move.

$\mathrm{m}=\mathrm{mass}$ of plate 
$=0.0175 \mathrm{~kg}$

$\mathrm{a}=$ acceleration of plate

Thus, summation of forces in $\mathrm{y}$ and $\mathrm{x}$ directions gives

$\sum$ Force $=\quad \mathrm{ma}$

$\sum F_{X} \quad=\quad \mathrm{P}-\mathrm{N} \quad=\quad$ ma

$\sum F_{Y} \quad=\quad-\mathrm{F}-\mathrm{N} \quad=\quad 0$ -

But $\quad \frac{T}{N}=f=0.5$

$$
\mathrm{T}=0.5 \mathrm{X} \mathrm{N}
$$

Solving for 'a' in equation (1), we have

$$
\begin{aligned}
& a \quad=\quad \frac{P-T}{m} \\
& =\quad \frac{5.92-(0.5 \times 12.5)}{0.0175}=18.9 \mathrm{~m} / \mathrm{s}^{2} \\
& \text { If } \quad X n=\text { displacement }
\end{aligned}
$$

Using equation of motion of object moving in a straight line

$V^{2}=U^{2}+2 \mathrm{ax}$

Where $\mathrm{V}$ and $\mathrm{U}=$ final and initial velocity respectively

Thus,

$\frac{V^{2}-U^{2}}{X_{2}-X_{1}} \quad=\quad 2 \mathrm{a}$

$2 a x_{2}=V^{2}$

Where

$X_{2}=$ distance moved by the top sliding plate which was approximately $80 \mathrm{~mm}=0.08 \mathrm{~m}$

$$
\begin{gathered}
V=\sqrt{2 \times 18.9 \times 0.08}=1.74 \mathrm{~m} / \mathrm{s} \\
\omega=\frac{V}{t}=\frac{1.74}{0.15}=11.6 \mathrm{rad} / \mathrm{sec}
\end{gathered}
$$

Recalling that $\omega=\frac{2 \pi N}{60}$

Where, $\mathrm{N} \quad=\quad$ number of revolutions per minute

Then power $\mathrm{P}$

$$
\begin{aligned}
\mathrm{N} & =\frac{60 X \omega}{2 \pi} \\
& =111 \mathrm{rpm}
\end{aligned}
$$

$=\mathrm{T} \omega$ 
The values determined for both power and number of motor revolutions will be the basis for choosing electric motor as a prime mover.

\subsubsection{Determination of feed rate}

Volume seed rate(Q) per minute will be

$$
Q_{m}=V_{f} \times N
$$

$=3.60 \times 10^{-4} \times 111=0.04 \mathrm{~m}^{3} / \mathrm{min}$

Feed rate per second will be

$$
\begin{aligned}
& =\quad \frac{0.04}{60} \\
& =\quad 6.67 \times 10^{-4} \mathrm{~m}^{3} / \mathrm{s}
\end{aligned}
$$

In mass per minute

$Q_{m / \min }=\quad$ bulk density $\times V_{f} \mathrm{XN}$

Thus

Bulk density of soaked seeds

volume of soaked seeds

$\mathrm{X}$

Volume of feeder

Where $\quad \mathrm{x}=$ bulk density of cowpea at a volume of $3.60 \times 10^{-4} \mathrm{~m}^{3}$

$$
\begin{aligned}
& \mathrm{X}=\frac{673 \times 3.60 \times 10^{-4}}{260 \times 10^{-6}} \\
& =\quad 932 \mathrm{~kg} / \mathrm{m}^{3}
\end{aligned}
$$

Therefore

$$
Q_{m / \min }
$$$$
=
$$$$
932 \times 3.60 \times 10^{-4} \times 111
$$$$
=\quad 37.2 \mathrm{Kg} / \mathrm{min}
$$

Thus,

$$
\frac{37.2}{60}=0.62 \mathrm{~kg} / \mathrm{s} \text { (mass per second) }
$$

3.2.9. Determination of the volume of Hopper.

The hopper has the shape of a frustum of a cone that is inverted, the volume will be:

$V_{h}=\frac{1}{3} X L^{2} \mathrm{H}-\frac{1}{3} \lambda^{2} \mathrm{~h}$

From fig.5 below:

$\mathrm{L}=$ length of upper section of the hopper $=\quad 0.3 \mathrm{~m}$

$\mathrm{L}=$ length of the lower section of the hopper $\quad=\quad 0.09 \mathrm{~m}$

The frustum abcd is obtained by removing bĉo from aôd, aôQ is similar to hop 


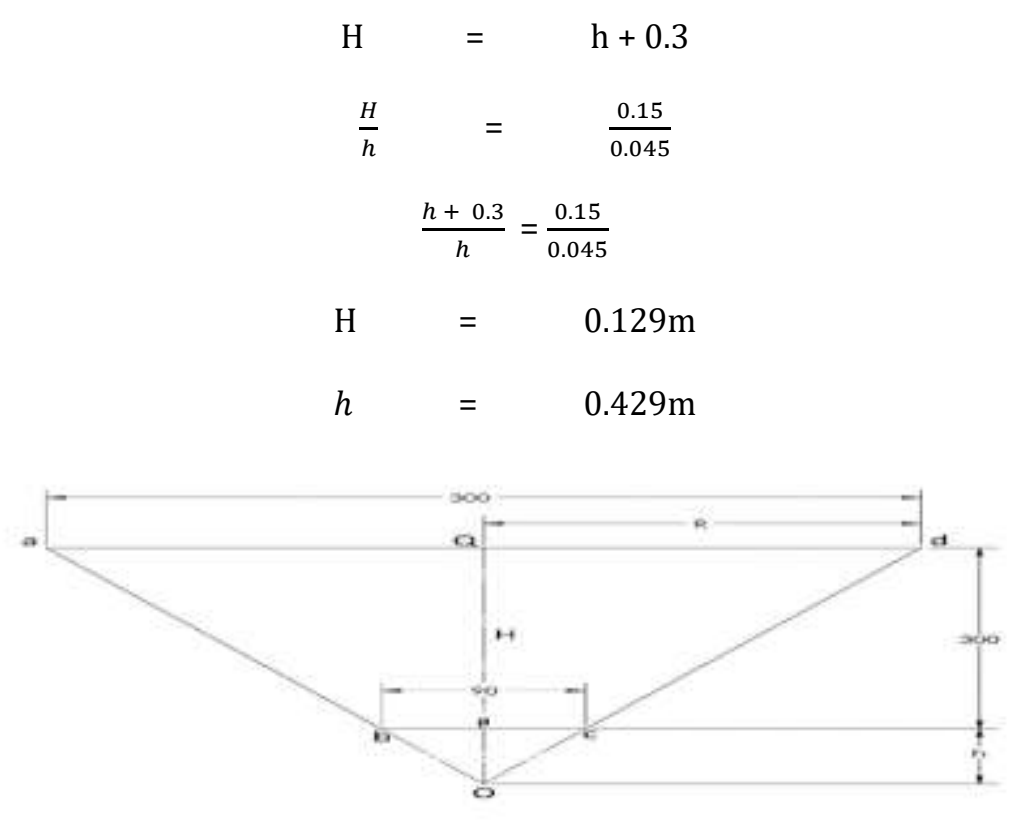

Figure 5:schematic view of a hopper

$$
\begin{aligned}
\text { Volume } V_{h} \quad=\quad & \frac{1}{3} 0.3^{2} \times 0.429-\frac{1}{3} 0.09^{2} \times 0.129 \\
& =\quad 0.01287-0.0003483 \\
& =\quad 1.25 \times 10^{-2} \mathrm{~m}^{3}
\end{aligned}
$$

Therefore, time $(t)$ taken for its content to finish if the stimulated time to finish dehulling after soaking of cowpea is 20 minutes for greater efficiently, which is suitable for optimal operating condition.

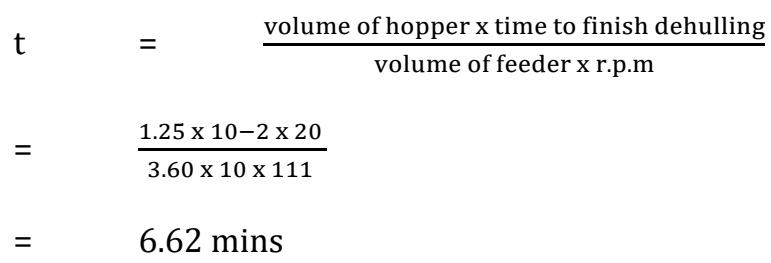

The FEA simulation report shows the contact pressure experienced by the cowpea due to the effect of the rotating plate and he fixed plate. Using the calculated torque to drive the plate $(T=5.36 \mathrm{Nm})$ and the coefficient of friction between the cowpea and plates as 0.5 . All material remain properties remain as specified in the material selections. 


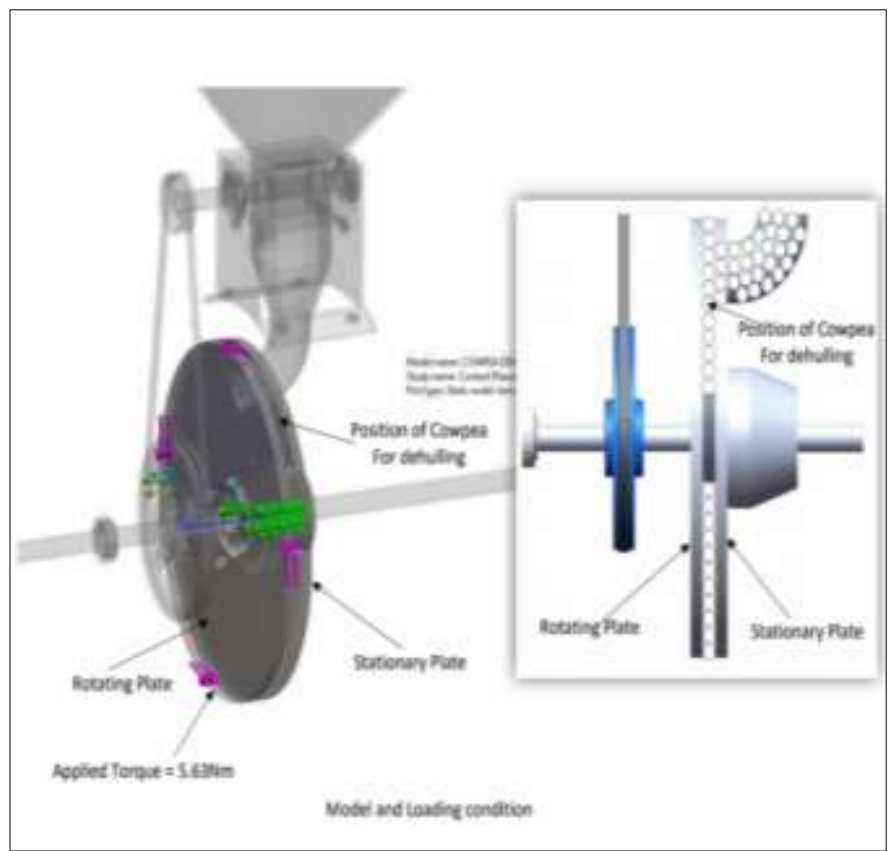

Figure 6 Model Loading Condition

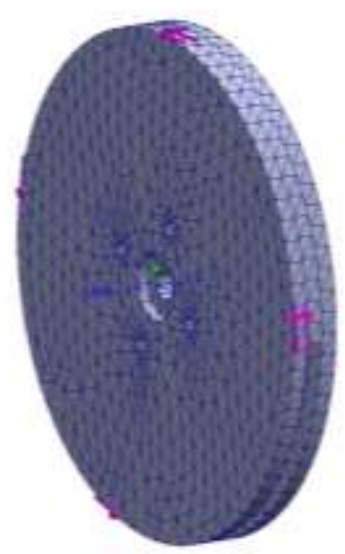

Figure 7 Mesh Model

Table 4 Mesh Design Information

\begin{tabular}{|l|l|}
\hline Mesh type & Solid Mesh \\
\hline Mesher Used: & Standard mesh \\
\hline Jacobian points for High quality mesh & 16 Points \\
\hline Element Size & $12.695 \mathrm{~mm}$ \\
\hline Total Nodes & 18461 \\
\hline Total Elements & 9483 \\
\hline Maximum Aspect Ratio & 7.3689 \\
\hline$\%$ of elements with Aspect Ratio $<3$ & 96.1 \\
\hline
\end{tabular}




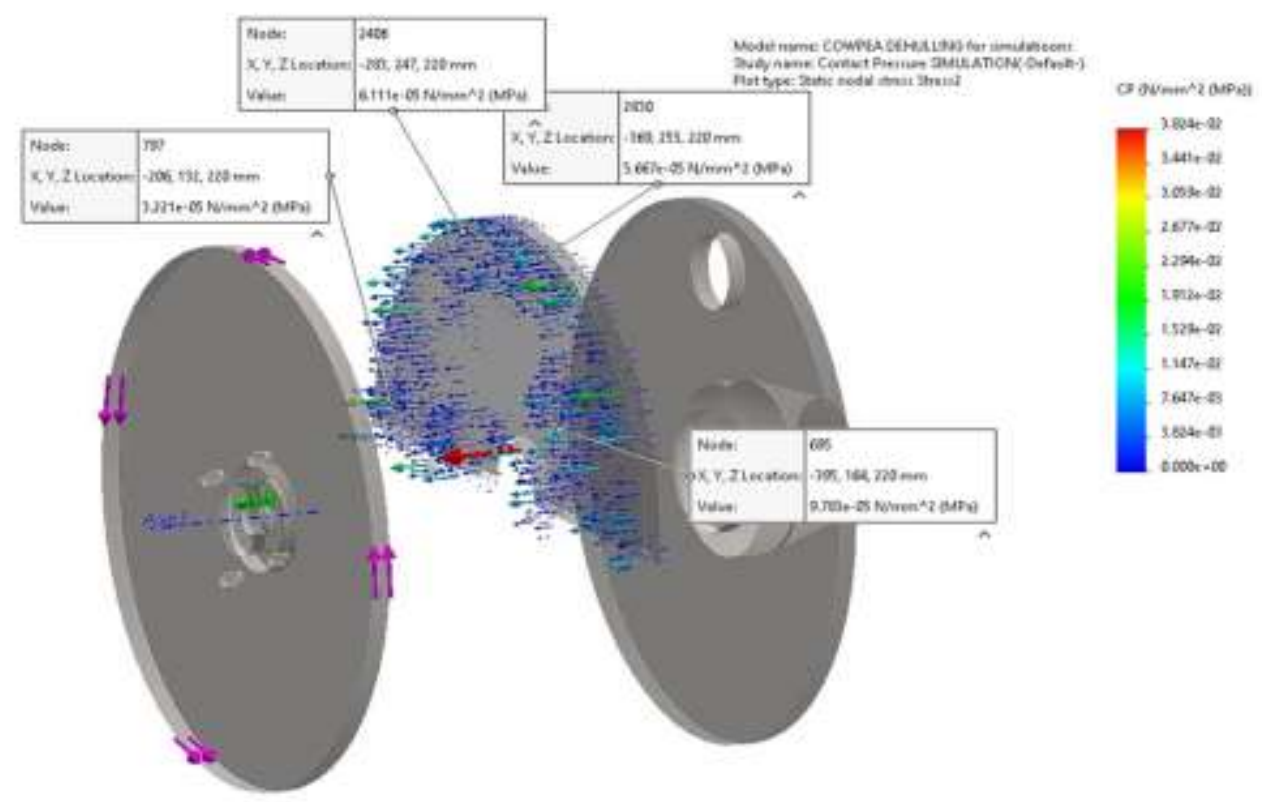

Figure 8 Static Nodal Stress Analysis Simulation

Table 5 Contact Pressure at different nodes (the region assumed to be occupied by the cowpea)

\begin{tabular}{|l|l|l|l|}
\hline \multicolumn{4}{|c|}{ Contact Pressure in $\times \mathbf{1 0}^{-\mathbf{5}} \mathbf{M P a}$} \\
\hline 3.221 & 6.111 & 5.667 & 9.783 \\
\hline
\end{tabular}

Average contact pressure obtained from simulation is

$$
\left(\frac{3.221+6.111+5.667+9.783}{4}\right) M P a=\frac{24.782}{4}=6.196 \times 10^{-5} M p a
$$

Average Contact Pressure $=6.196 \times 10^{-5} \mathrm{Mpa}=61.96 \mathrm{Nm}^{2}$

To obtain the force,

$$
F=\text { ObtainedAveragePresseure } \times \text { surfaceAreaoftheplatesmakingcontactwiththecowpea }=
$$

$=61.96 \mathrm{Nm}^{2} \times 0.14 \mathrm{~m}^{2}=8.674 \mathrm{~N}$

Comparing the calculated value of force needed to dehull the cowpea successfully to the force obtain from the simulation results.

Calculated Valve $=5.92 \mathrm{~N}$ to $12.5 \mathrm{~N}$

Obtained Valve from simulation $=8.674 \mathrm{~N}$

Force that will crush soaked cowpea is when it exceeds $15.8 \mathrm{~N}$ under dynamic load (plate sliding), but about $50 \mathrm{~N}$ under static load.

Hence, the obtained force from the Contact pressure simulation is acceptable for safe operation of the Dehulling Machine. 


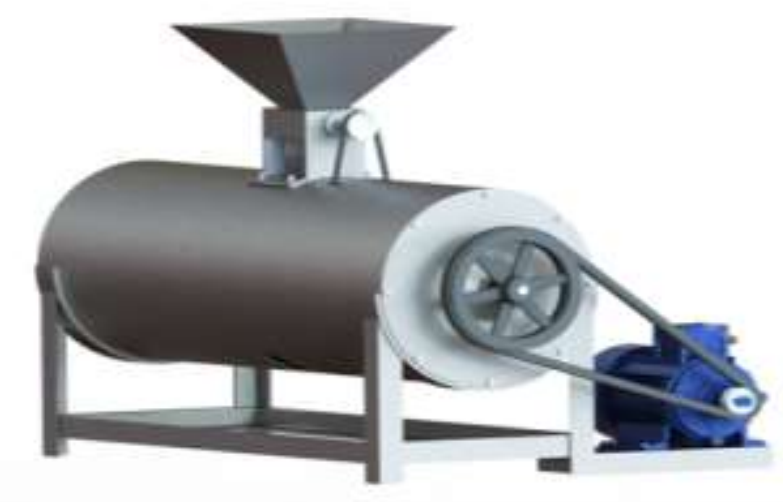

Figure 9 Simulated Cowpea Dehulling Machine
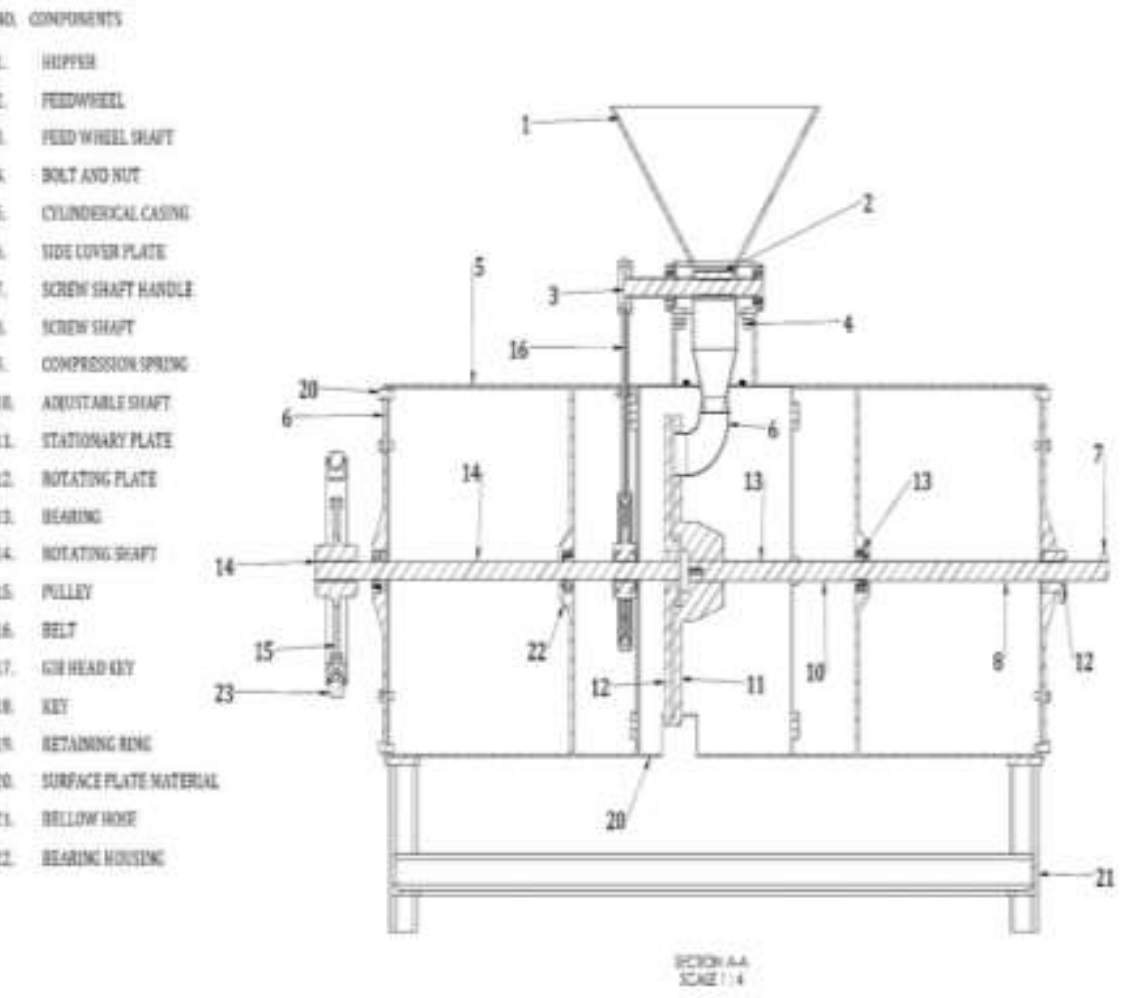

Figure 10 Schematic Diagram of Cowpea Dehulling Machine 


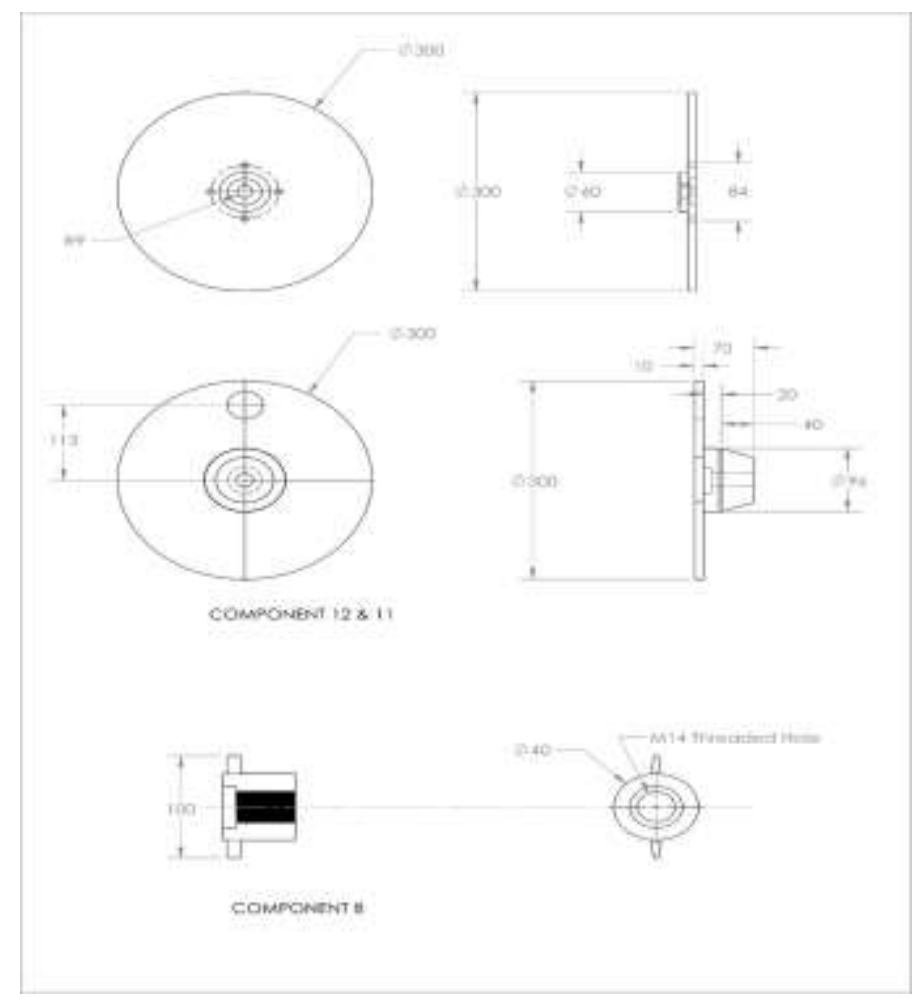

Figure 11 Schematic Diagrams of Machine Components

\section{Conclusion and recommendation}

The result showed that the machine have dehulling efficiency of $79 \%$ with a corresponding machine efficiency $81.25 \%$. This tends to show that if the machine is be commercialized, cowpea utilization will be increased.

The cowpea dehulling machine will be effective in rural and urban area, especially in the small-scale cowpea processing industry due to its low, simple, profitable and efficient design.

The machine was designed considering the conditions and Size of soaked cowpea as design parameters thus a high level of performance will be obtained, if the machine is use to dehull cowpea according to the design specifications. The machine is restricted to dehulling of only wet seeds.

\section{Compliance with ethical standards}

\section{Acknowledgments}

The authors wish to acknowledge the support of Nigeria Maritime University, Okerenkoko,Delta State, Nigeria in providing the enabling environment for carrying out the research.

\section{Disclosure of conflict of interest}

There was no conflict of interest by the authors in the preparation and submission of this paper

\section{References}

[1] Tharanathan RN, Mahadevamma S."Grain legumes-A boon To human nutrition. Trend food Sci.Tech. $2003 ; 14$ (12): 507-518.

[2] Akpapunam MA, Sefa-Dedeh J. "Bean (Canavalia ensiformis) Nutrition-related aspect and needed research. Plant Food Hum.Nutri. 1997; 10: 123-127. 
[3] Aduba JJ, Olutu FB, Olaoye JO. "Effect of Operative processing conditions on the performance of Cowpea Dehuller" Intl Journal of basic and applied Science. 2003; 2(3): 71-78.

[4] Fawohunre AJ Olajide OG."Development and performance of a motorized cowpea threshing machine for smallscale farmers in Nigeria.Global journal of Engineering and Technology. 2020; 05(01): 001-007.

[5] Udofia ND."Grinding Technology”,Apex Pringting press Nigeria. 2020.

[6] Kordylas JM."Processing and preservation of tropical and sub-tropical foods Macmillian Education Limited. 1990.

[7] Spott MF. Design of Machine Elements (6 th $^{\text {th }}$ Edition) Mohan Makhi Jani Publishing Co. New Delhi, India. 1988.

[8] Levinson I. Machine Design, Reston Publishing Company Inc.USA. 1978.

[9] Ryder GH. Strength of Materials, Macmillan Education Press Ltd, Basingstoke. 1969.

[10] Hannah J, Stephens RC. Mechanics of Machine, (4th Edition) Edward Arnold Publishers, Great Britain. 1984. 